\title{
PANORAMA CONTEMPORÁNEO DEL ORDENAMIENTO ECOLÓGICO TERRITORIAL EN MÉXICO.
}

\author{
José Ramón HERNÁNDEZ SANTANA \\ santana@igg.unam.mx \\ Instituto de Geografía, Universidad Nacional Autónoma de México (UNAM)
}

\author{
Manuel BOLLO MANENT \\ mbollo@ciga.unam.mx \\ Centro de Investigaciones en Geografía Ambiental, Universidad Nacional \\ Autónoma de México (UNAM)
}

Ana Patricia MÉNDEZ LINARES

patyml@igg.unam.mx

Instituto de Geografía, Universidad Nacional Autónoma de México (UNAM)

Luis Miguel ESPINOSA RODRÍGUEZ

geo_luismiguel@hotmail.com

Facultad de Geografía, Universidad Autónoma del Estado de México (UAEM)

Recibido: $28 / 02 / 2014$

Aceptado: 15/10/2014

RESUMEN: Transcurridas varias décadas de experiencias en materia de ordenamiento ecológico territorial, se sintetizan los resultados más notables en la mayoría de los países latinoamericanos y, en especial, se aborda exhaustivamente el panorama de estos procesos de planeación territorial en el caso mexicano, donde desde los años setenta y hasta el presente, se desarrollan notables esfuerzos en esta dirección. El dinamismo institucional y legislativo del país, desde la primera mitad del siglo XX, unido a una extensiva participación democrática de la sociedad y de todos los sectores y actores involucrados, ha permitido la existencia del Programa de Ordenamiento Ecológico General del Territorio (2012), de los ordenamientos ecológicos marinos del Golfo de México y Mar Caribe (2012), del Golfo de California (2006), de 40 ordenamientos ecológicos regionales, 60 locales y 287 comunitarios, estos últimos cubren la mitad del territorio nacional. Finalmente, se consideran diversos aspectos de carácter filosófico, educativo, formativo, político-ejecutivo y participativo, que deben perfeccionarse para cristalizar la viabilidad futura de la ordenación del territorio en México.

PALABRAS CLAVE: ordenamiento ecológico territorial, instituciones gubernamentales, México. 


\section{CONTEMPORARY OVERVIEW OF TERRITORIAL ECOLOGICAL PLANNING IN MEXICO}

ABSTRACT: After several decades of experiences in environmental land use planning, the most notable results in many Latin American countries are synthesized. A thorough review is presented for Mexico, where notable efforts in this matter have been made since the 1970s. The institutional and legislative dynamism of the country from the first half on the $20^{\text {th }}$ century, tied with extensive democratic participation of society and all involved sectors and actors, has enabled the existence of the Mexican Environmental Land Use Planning Program (2012), the marine environmental planning of the Gulf of Mexico and Caribbean Sea (2012) and the Gulf of California (2006), as well environmental land use planning programs at regional (40 cases), local (60) and community (287) levels. The last three types cover half of the national territory. Finally, the authors consider philosophical, educational, training and political participatory aspects that require improvement in order to increase the feasibility of environmental land use planning in Mexico.

KEY WORDS: territorial ecological planning, government institutions, Mexico.

\section{INTRODUCCIÓN}

Una de las regularidades comunes del desarrollo del proceso de ordenamiento territorial en la mayoría de los países latinoamericanos fue su surgimiento, a partir de los esfuerzos y de las experiencias en la planificación física, y de la visión de los proyectos arquitectónicos y funcionales de los espacios urbanos, dirigidos en el mayor número de los casos por arquitectos y, en ocasiones, en conjunto con abogados e ingenieros. Esta situación, imperante durante la primera mitad y parte de la segunda del siglo XX, se enraizó debido a la naciente institucionalidad de la geografía científica y, por ende, al incipiente despegue de las investigaciones geográficas, tanto teórico-metodológicas como aplicadas, sobre la estructura, el funcionamiento y la dinámica de los factores naturales y sobre los actores sociales y económicos en el contexto espacial. En las últimas décadas de dicho siglo e inicios del actual, el papel del geógrafo y de otros naturalistas y cientistas sociales, ha cobrado fuerza dentro de los procesos de ordenamiento territorial, gracias al carácter holístico e integral de la geografía, a la trascendencia de los aportes de diversas disciplinas ocupadas en la gestión ambiental, en la evaluación y formulación de planes de ordenamiento del territorio, en diversas escalas espaciales.

En América Latina, según Massiris (2012: 19) han transitado secuencialmente y, en ocasiones al unísono, diversas estrategias territoriales, como "desarrollo regional, planificación del uso del suelo urbano, descentralización y desarrollo territorial" y más recientemente, el ordenamiento territorial. De manera general, esta nueva estrategia se desarrolla a diferentes escalas y en correspondencia con los criterios de las divisiones político-administrativas de los países: (a) planes nacionales de ordenamiento territorial, a escalas pequeñas, para generar visiones 
estratégicas a los gobiernos centrales y federales; (b) planes regionales de ordenamiento territorial, conectados a decisiones y propósitos de planeación territorial de regiones, provincias y/o estados, en el caso de naciones federativas, siempre a escala media; (c) planes municipales o locales de ordenamiento territorial, a escala detallada; (d) planes comunitarios, en el contexto de lo micro-territorial, a escala muy detallada; y los planes de ordenamiento territorial marinos, a escalas media y pequeña, según la superficie de las cuencas marinas u oceánicas involucradas.

En este sentido, resulta importante reconocer las diferencias territoriales, debido entre otras razones, a que la región latinoamericana es muy diversa desde el punto de vista físico-geográfico, formada además por países de dimensiones continentales, ístmicas e insulares diferentes; con historias y procesos políticos distintos, unidos de cierta manera en la matriz cultural, pero no en el desarrollo sociopolítico, lo que genera disímiles modos de instrumentar e implementar las políticas públicas en la dimensión de sus territorios. A continuación, se esboza en un ejercicio de síntesis, el comportamiento del ordenamiento territorial en algunas naciones, y se incursiona más detalladamente en el panorama mexicano.

\section{ORDENAMIENTO TERRITORIAL: UNA RAUDA MIRADA POR PAÍSES LATINOAMERICANOS}

\section{II.1 República Federativa de Brasil}

En la década de los años treinta, Brasil comenzó a adoptar políticas referidas al ordenamiento territorial creándose el Instituto Nacional de Estadística en 1934, y el Consejo Nacional de Geografía; ambos se fundieron como el Instituto Brasilero de Geografía y Estadística (IBGE), en el año 1937, para regir la generación, organización y procesamiento de la información estadística en materia económica, social y demográfica (PEREIRA, 2004: 4). En general, según este especialista, las investigaciones sobre la ordenación territorial tomaron dos vertientes: la integración nacional y el desarrollo regional, enfocándose a unidades federales, mesorregiones, microrregiones, municipios, distritos, sectores rurales y urbanos. Actualmente, se gestan los denominados Planes Directores Municipales, en la mayoría de los municipios.

El tema de la gestión territorial en Brasil está contemplado en los artículos 182 y 183 de su constitución, como herramienta para la política ambiental (FUNDACIÓN CAMBIO DEMOCRÁTICO, 2010: 44) y centró la agenda guberna- 
mental en diferentes momentos históricos: en el año 1981, la ley 6.938 adopta la zonificación ecológica económica como instrumento de gestión ambiental de los territorios, bajo la responsabilidad del Ministerio del Ambiente y la ejecución de los estados (MASSIRIS, 2013: 29); en el año 1988, fue considerado en la nueva Carta Magna; en el 2003, fue contemplado en la ley 10.683/03, que define las atribuciones ministeriales y confiere la responsabilidad al Ministerio de Integración Nacional; durante el año 2004, se establece la propuesta de Política Nacional del Ordenamiento Territorial, en el referido ministerio gestor (De CÁsSIA, 2010: 126), y en la perspectiva regional, muchas ideas y esfuerzos luchan por "terminar con las desigualdades regionales, para tener de esta forma un adecuado desarrollo territorial del país" (LIRA, 2009: 135). A pesar de los esfuerzos emprendidos a partir de 1950, con la ejecución de planes urbano-regionales, de los planes de desarrollo económico y social, y del Programa de Integración Nacional, DE CÁSSIA (2010: 124) expone que persisten problemas de falta de coordinación gubernamental en la gestión de los territorios; ausencia de sinergias intersectoriales; presencia de numerosos conflictos sectoriales y sociales; desarrollo de un modelo de ocupación ambientalmente incompatible, con deforestación intensa con la consiguiente expansión de la frontera agrícola; entre un amplio abanico de dificultades para poder alcanzar una visión viable del desarrollo sostenible nacional y regional. No obstante, en el contexto del territorio andino-amazónico, Brasil ha alcanzado los principales logros, pues el ordenamiento territorial en la Amazonía constituye una política de estado (IIAP et al., 2010).

La política de gestión territorial del estado de Amazonas, implementada a partir de la década del 70, se ha basado en procesos de desarrollo de políticas agrarias y ambientales (Fernandes et al., s/f: 57). Según estos especialistas estos proyectos continúan siendo desarrollados bajo una visión conservacionista, bajo los Programas de Desarrollo Sostenible, que persiguen la implantación de unidades de conservación, buscando el desarrollo de las poblaciones locales y la conservación de la biodiversidad. En general, la problemática del ordenamiento territorial brasileño persigue la desconcentración de la región costera, el sur y el sudeste del país, asegurando la integración del semiárido de la región nordeste al centro de Brasil y de la región amazónica, bajo la perspectiva de la preservación ambiental, de la manutención de la soberanía e integridad del territorio nacional y de la integración con los países del continente (TorRes-FiLHo, 2010).

\section{II.2 República Argentina}

Desde los años cincuenta, el gobierno argentino orientó la política territorial hacia la planificación urbana (MAssiRIS, 2006), y los primeros logros en 
materia de ordenamiento territorial y usos de suelo surgieron con la promulgación de la Ley 8912 de 1977, por la provincia de Buenos Aires, y en el año 2001, con la proposición senatorial de una Ley Orgánica de Ordenamiento Territorial, como plataforma jurídica de la política estatal en materia de desarrollo territorial (MARINA-BERÓN et al., 2013: 101-102).

Dadas las condiciones de asimetría económica y social, tanto a nivel nacional como regional, y considerando los compromisos sociales y políticos de la plataforma gubernamental actual, el gobierno nacional ha definido una Política Nacional de Desarrollo y Ordenamiento Territorial de largo plazo, que permitirá superar las limitaciones y deficiencias históricas, y que servirá para sustentar el conjunto de las políticas nacionales, provinciales, municipales y sectoriales de desarrollo, de manera de lograr un territorio más equilibrado, integrado, sustentable y socialmente justo; consolidando una visión transversal de estrategias y acciones intersectoriales, que estreche la brecha de desigualdades entre las provincias y sus municipios, acercando las políticas a un desarrollo más armónico y consensuado entre todos los actores territoriales. Estos propósitos se plasman en el modelo de nación denominado "Argentina 2016", como expresión de equilibrio, integración, sustentabilidad y justicia social (MINISTERIO DE PLANIFICACIÓN FEDERAL, INVERSIÓN PÚBLICA Y SERVICIOS DE PLANIFICACIÓN FEDERAL DE ARGENTINA, 2014: 16, 21).

Desde la óptica gubernamental provincial y, a manera de ejemplo, en el año 2009, el gobierno de la provincia de Mendoza promulgó la ley 8051/09 “Ley de Ordenamiento Territorial y Usos del Suelo", como marco jurídico para la planeación y gestión territoriales (MARINA-BERÓN et al., 2013: 98), centrados también en la visualización del modelo "Mendoza 2030". Estos planes provinciales presentes en muchas provincias reconocen tres etapas básicas de implementación: planificación estratégica del desarrollo, ordenamiento territorial provincial y ordenamiento territorial municipal (GOBIERNO DE MENDOZA, 2014). En general, se reconoce que los avances en materia de ordenamiento territorial en Argentina han sido escasos, aunque ya existen los marcos jurídicos necesarios, la institucionalidad ejecutiva gubernamental indispensable y la voluntad de participación democrática de la ciudadanía.

\section{II.3 República Bolivariana de Venezuela}

En Venezuela, el interés por la dimensión territorial del desarrollo cobró auge en la década de los años 60 (MÉNDEZ, 2000: 281), dirigido fundamentalmente a la corrección del uso del suelo y ocupación inadecuada (MASsiRIS, s/f, a: 1). El 26 de julio de 1983, el Congreso de la República de Venezuela promulgó la "Ley 
Orgánica para la Ordenación del Territorio-(LOOT)", siendo la primera de su tipo en América Latina (Colonnello y Salas-Dueñas, 2004: 6; Morales, 2012: 14; MASSIRIS, $\mathrm{s} / \mathrm{f}, \mathrm{b}: 1)$. Esta ley contempla los instrumentos siguientes en su artículo 5: Plan nacional de ordenación del territorio, planes regionales, planes nacionales de aprovechamiento de los recursos naturales y planes sectoriales, planes de ordenación urbanística, planes de las áreas bajo Régimen de Administración Especial y los demás planes de la ordenación del territorio, que demande el proceso de desarrollo integral del país (REPÚBLICA DE VENEZUELA, 1983: 1); la cual se aplica bajo un prisma de desarrollo integral en el estado de Táchira (MASsiRIs, s/f, b: 1). Salas y Sulbarán (2011: 34) señalan que con la entrada en vigor de la Constitución de la República Bolivariana de Venezuela (2000), la ordenación del territorio ocupó uno de los sitios cardinales de la gestión pública en el país; sin embargo, luego de diversos intentos de modificación después de 30 años (proyectos del 2002, 2005, 2007, 2008 y 2009), la Ley Orgánica para la Ordenación del Territorio sigue en pleno ejercicio, quizás "por un interés que va más allá de la regulación de la ocupación del territorio, como parte del proceso de desarrollo nacional, para abarcar la pretensión de control político del territorio por parte del gobierno a través de novedosas instituciones de gestión territorial, cuyo propósito dista de la naturaleza de la ordenación del territorio".

Venezuela, al igual que otros países latinoamericanos durante el siglo XX, transitó a través de diversas etapas hacia la gestión territorial, desde la creación de las primeras áreas naturales protegidas y el establecimiento de planes de desarrollo económico hasta la promulgación de múltiples normas jurídicas en la segunda mitad de siglo, tales como, la Ley de Reforma Agraria (1960); la Ley Forestal de Suelos y Aguas (1966); la Ley Orgánica del Ambiente (1976), con su programa "Ordenación de la Ocupación del Territorio Nacional" (1977), destinado a la formulación del primer Plan Nacional de Ordenación del Territorio; la Ley Orgánica para la Ordenación del Territorio (1983); la creación y sanción del primer Plan Nacional de Ordenación del Territorio (1998) (SAlas y Sulbarán, 2011: 36-38); así como, la Ley Orgánica para la Planificación y Gestión de la Ordenación del Territorio (Gaceta Oficial 5.820 del 1ro. de septiembre del 2006), y la Ley Derogatoria de la Ley Orgánica para la Planificación y Gestión de la Ordenación del Territorio (Gaceta Oficial 38.633 del 27 de febrero de 2009) (VILANOvA, 2014). El Plan Nacional de Ordenación del Territorio del año 1998 constituyó una certera iniciativa y es un insumo vigente en la estrategia de descentralización del desarrollo (CABRERA, 2012: 3). En los últimos años, sobre todo después del rechazo de la reforma constitucional en el año 2007, el gobierno venezolano ha estado inmerso en la búsqueda de instrumentos legales para el control centralizado del territorio nacional acordes con el deseo de la conformación socialista de la nación. Todo esto genera "cambios en los principios y los valores democráticos, y del respeto 
a la propiedad privada, condición que distorsiona los principios de seguridad jurídica necesarios para el crecimiento y desarrollo del país" (ORNÉs, 2009: 221), aspectos que se manifiestan en las actuaciones gubernamentales hasta el presente.

Desde el punto de vista de la formación universitaria, actualmente la Universidad Bolivariana de Venezuela, se centra en la graduación de gestores ambientales, enfocados a la planificación, control y manejo del espacio geográfico, dentro de su unidad curricular sobre Ordenación Territorial Ambiental (ARAQUE y YAJAIRA, 2006: 2), lo que indiscutiblemente fortalecerá, aun más, la visión académica, cultural y práctica de tan importante disciplina, esencial para el desarrollo sostenible de la nación.

\section{II.4 República de Colombia}

En Colombia, la ley 388 del 24 de julio de 1997 (REPÚBLICA DE COLOMBIA, 1997), propició el desarrollo de los planes de ordenamiento territorial municipales y distritales, sobre la plataforma de la normativa de la tipología y la regularización del uso de suelo y el manejo del espacio público, pero en sus inicios obstáculos disímiles frenaron el éxito de sus propósitos, tales como la carencia de bases conceptuales, metodológicas y técnicas sobre la ordenación territorial, escasez de recursos financieros, inexistencia de series cartográficas o en su lugar desactualizadas, ausencia de personal calificado y experimentado en la naciente temática, además del conflicto armado gestado en 1960 y que perdura en el tiempo presente (Massiris, 2009:15). Por supuesto, los antecedentes de dicha ley del año 1997, como señala el autor, descansan en el Código Sanitario (1979), el Código de Régimen Municipal (1986) y la Ley de Reforma Urbana (1989).

Según los criterios de MASsiRIS (2009: 17), un rol importante desde el punto de vista conceptual y metodológico fue desempeñado por el Instituto Geográfico “Agustín Codazzi" desde los años ochenta del siglo XX y hasta el año 1997, con la creación de las guías para el ordenamiento urbano, municipal y departamental. Esta institución se destacó en la formación de profesionistas latinoamericanos, en la transferencia científica y tecnológica para el análisis geoespacial del territorio, bienvenida en países como Cuba, donde muchos geógrafos alcanzaron estudios de posgrado después de los años noventa.

Los obstáculos para emprender la formulación de los planes de ordenamiento territorial municipales fueron notables, dada la inexperiencia en la actividad y la carencia de personal calificado para ello; MAssiRIs (2009: 19-20) resalta que de los 1098 municipios del país, en 1999, sólo 31 habían adoptado 
legalmente sus planes, pero en el 2005, el $93 \%$ de los mismos ya alcanzaron la formulación de sus planes.

\section{II.5 República de Cuba}

En las condiciones socialistas cubanas, desde los inicios de las transformaciones revolucionarias del año 1959, surge la planificación física centralizada como actividad estatal dirigida a la macro y microlocalización de la producción y de los asentamientos humanos, velando por la utilización racional de los recursos naturales y la protección del medio ambiente. Bajo esta óptica, desde el 19 de mayo de 1960 surge el Instituto de Planificación Física (IPF), para ser fundado el 30 de noviembre de 1976. El 9 de marzo de 1978 aparece en la Gaceta Oficial, el acuerdo 21/78 del Consejo de Ministros, donde se define el Reglamento de la Planificación Física del país. Esta ordenanza contempló los planes como nacional, regionales y directores urbanos (por ejemplo, Plan Director de la ciudad de La Habana, Santiago de Cuba) en la categoría I; los planes directores de capitales provinciales, y los proyectos de zona, urbanísticos o agropecuarios, en la categoría II; los planes directores de ciudades mayores de 20000 habitantes y los proyectos de zonas turísticas nacionales, en la categoría III; los planes directores urbanos de cabeceras municipales, centrales azucareros y nuevos pueblos mayores de 1000 habitantes, en la categoría IV; y otros núcleos urbanos pequeños y zonas agropecuarios de incidencia local, en la categoría V (GonZÁLEZ, 2009: 49). En los albores, la institución se dividía en dos direcciones, la de planes urbanos y la de planes regionales, para posteriormente como sistema de planificación física nacional, consolidarse en las direcciones provinciales y municipales, artífices de los proyectos de los programas socioeconómicos, las regulaciones urbanas y la aprobación de microlocalizaciones, todas robustecidas con las licencias ambientales, emitidas por la Agencia de Medio Ambiente, a partir del año 1995. El IPF siempre ha velado por la planificación física y el ordenamiento territorial, pero no vinculado con el ecológico o ambiental, que surge con la ley $\mathrm{n}^{\circ} 81$ "Ley del Medio Ambiente", del 11 de julio de 1997.

La planificación física cubana contribuyó a la división político-administrativa del país y a la regionalización económica nacional; a la organización territorial de los sectores agropecuario, agroindustrial azucarero, turístico e industrial; al análisis del sistema urbano nacional; al establecimiento del Sistema de Información Territorial; a la investigación sobre los efectos del cambio climático y los riesgos naturales, sobre todo en las zonas costeras; a la localización de inversiones; y a otras tareas de planeación territorial. De forma paralela y a partir del año 2007, la Agencia de Medio Ambiente y el Instituto de Geografía Tropical, han 
establecido la guía metodológica para el ordenamiento ambiental del territorio cubano, como respuesta a lo enunciado en la Ley de Medio Ambiente (CÁrdenas, 2014). Esta guía persigue privilegiar la dimensión ambiental en el contexto del sistema de planificación física nacional, priorizando las investigaciones y proyectos de restauración, protección y conservación del patrimonio natural de la nación.

\section{II.6 República del Ecuador}

La Constitución de la República del Ecuador, aprobada en referéndum constitucional el 28 de septiembre del 2008, plantea en su artículo 241 "La planificación garantizará el ordenamiento territorial y será obligatoria en todos los gobiernos autónomos descentralizados", así como, en el capítulo cuarto, relativo al régimen de competencias, en que los Gobiernos Autónomos Descentralizados (GAD) deben planificar el desarrollo y formular los correspondientes planes de ordenamiento territorial, de manera articulada con la planificación nacional, regional, cantonal y parroquial (SотомаYOR, 2014), garantizando las premisas básicas de la ordenación del territorio.

De acuerdo con el análisis de la planificación territorial en el Ecuador (LoZANO, 2013: 4), ésta se institucionalizó hace más de cinco décadas, con la creación de la Junta Nacional de Planificación y Coordinación Económica (JUNAPLA), en el año 1954, con la encomienda de la planificación nacional (Plan Nacional de Desarrollo, PND). Posteriormente, el potencial institucional se valorizó con la creación del Consejo Nacional de Desarrollo, CONADE (1979), que generó el PND y formuló los Planes de Desarrollo Regionales, apoyado por organismos de la Organización de Estados Americanos (OEA), el Fondo Nacional de Pre-inversión (FONAPRE), con notable actividad en la década de los años ochenta, sobre todo en el financiamiento de los planes de desarrollo urbano a nivel municipal.

En el año 1995, se crea la Oficina de Planificación de la Presidencia de la República (ODEPLAN), que con fondos del Banco Interamericano de Desarrollo (BID), organizó el Primer Encuentro Nacional sobre Ordenamiento Territorial (1997), oficina que se ocupó de la ejecución de los planes de desarrollo provincial. El 30 de julio de 1999, promulgó la "Ley de Gestión Ambiental" (Registro Oficial $\mathrm{n}^{\circ}$ 245, del 30 julio de 1999), que dispone al Ministerio de Medio Ambiente, la elaboración de la Estrategia Nacional de Ordenamiento Territorial y los planes seccionales. En el presente, la Secretaria Nacional de Planificación y Desarrollo (SENPLADES, 2007: 12) ejecuta el Plan Nacional de Desarrollo 2007-2009, y el Plan Nacional del Buen Vivir 2009-2013, que incluye la Estrategia Territorial Nacional (LozANo, 2013: 5). Los retos fundamentales para poder 
cristalizar esta filosofía plurinacional y pluricultural de la Pachamama o Madre Tierra, en la gestión sustentable del territorio ecuatoriano, descansan en el aprovechamiento racional de los recursos naturales existentes, en el fortalecimiento de la base científico-técnica de la nación y en la garantía de un sistema de participación democrática, que respete los derechos ciudadanos a las decisiones del bienestar ambiental y de su calidad de vida.

\section{II.7 República del Perú}

El punto de partida del ordenamiento territorial en el Perú es la Constitución de 1993, donde se vincula el aspecto del ambiente, el territorio y los recursos naturales, entre otros muchos; además, Perú cuenta el Reglamento de Zonificación Ecológica Económica, los Lineamientos de Política para el Ordenamiento Territorial y la Propuesta de Estrategia Nacional de Zonificación Ecológica Económica, elaborada en la primera década del 2000 (AzPuR, 2011: 3-4). Por otra parte, "la Ley Orgánica de Bases de la Descentralización y la Ley de Demarcación y Organización Territorial, ambas promulgadas en julio de 2002, establecen los principios, objetivos y criterios generales del proceso, así como las competencias del gobierno nacional y los gobiernos subnacionales, la cual define el ordenamiento del territorio y del entorno ambiental; el desarrollo económico autosostenido y la competitividad de regiones y localidades, a partir de su vocación productiva, así como la gestión sostenible de los recursos naturales y la mejora de la calidad ambiental" (AzPuR, 2011: 8, 12). No obstante, como casi todos los procesos de ordenamiento territorial en América Latina, existen marcadas posiciones entre regiones "desarrollistas", grupos ambientalistas "conservacionistas extremos". Según este experto, existen otros conflictos por falta de capacitación y de metodologías claras y uniformes para un mejor entendimiento, lo que determinó en gran medida las dificultades presentadas en las fases de modelación y la de validación de la propuesta de zonificación ecológica económica.

\section{II.8 República Oriental del Uruguay}

La Ley de Centros Poblados, aprobada en 1946, sustituyó al Reglamento de la antigua Ley de Indias del año 1877, pero realmente Uruguay abordó el ordenamiento territorial con "la Ley 18.308 de Ordenamiento Territorial y Desarrollo Sustentable, vigente desde el 30 de junio de 2008 y reglamentada por el Decreto $\mathrm{n}^{\circ} 221$ del año 2009, que consta de 83 artículos que definen los fines y la naturaleza del ordenamiento territorial, los derechos y deberes territoriales de las personas y de la propiedad inmueble, los instrumentos de la planificación en sus diversas escalas, los criterios generales que ordenan los usos de suelo y controlan 
su sostenibilidad y los mecanismos de participación social y de coordinación institucional" (MVOTMA, 2010: 5-6). Según este Ministerio, el ordenamiento territorial posee las escalas nacional, regional y departamental. Uno de los planes mejor logrado en Uruguay es el de Montevideo, a partir de 1998, que armoniza con la protección y desarrollo del patrimonio natural circundante.

\section{II.9 República de Chile}

En Chile, el enfoque territorial de la Administración del Estado distingue cuatro niveles: nacional, regional, provincial y comunal. En el nivel regional, la Ley $\mathrm{n}^{\circ} 19.175$ establece las políticas y objetivos para el desarrollo integral y armónico del sistema de asentamientos humanos; participa en coordinación con las autoridades nacionales y comunales competentes en programas y proyectos de obras de infraestructura y equipamiento; fomenta y vela por la protección, conservación y mejoramiento del medio ambiente, adopta las medidas adecuadas a la realidad regional con sujeción a las normas legales y decretos supremos reglamentarios que rijan la materia; fomenta y vela por el buen funcionamiento de la prestación de servicios en materias de transporte; fomenta y propende el desarrollo de áreas rurales y localidades aisladas; y promulga, previo acuerdo del Consejo Regional, los planes reguladores metropolitanos, intercomunales, comunales y seccionales conforme a las normas de la Ley General de Urbanismo y Construcciones (CEPAL, 2011: 23-24).

A finales del año 2003 y bajo el auspicio de la Subsecretaría de Desarrollo Regional, se ha desarrollado el Programa de Gestión Territorial Integral, enfocado a enfrentar la descoordinación y ambigüedad de funciones de los organismos de gobierno en los territorios (ITURRIAGA, 2003: 120) y contribuir a la descentralización (WERNER et al., 1995: 59), por la vía de generar capacidades de análisis de los procesos de gestión y aplicación de instrumentos de colaboración interinstitucional, coordinando la oferta pública de productos y de servicios en el territorio, integrando instrumentos de planificación y compatibilizando la programación operacional del gasto público (Cox, 2008: 19). En este sentido, la modalidad de ordenamiento territorial en Chile está dirigida a privilegiar el desarrollo integral y sostenido de sus asentamientos humanos y sus hábitats, para lo cual se adopta como unidad básica de gestión a las 15 regiones político-administrativas, vigentes actualmente, siempre bajo un enfoque democrático y moderno (LóPEZ, 2011: 33), en consonancia con el Plan Regional de Ordenamiento Territorial, normado por la Subsecretaría de Desarrollo Regional y Administrativo (Subdere, 2011). Un ejemplo destacado por MALLEA (s/f: 18) es el proyecto OTAS, sobre ordenamiento territorial ambientalmente sustentable en la Región Metropolitana de 
Santiago, que contribuyó al fomento de la sinergia entre la gestión ambiental y la planificación territorial por medio de la planificación ecológica.

Desde el punto de vista local y comunitario indígena, la WWF de Chile desarrolla el proyecto "Modelo de áreas conservadas por comunidades indígenas para el desarrollo del ecoturismo y la conservación de la biodiversidad", articulando mecanismos efectivos de gobernanza, de ordenamiento y gestión territoriales y de seguridad de los derechos territoriales, mediante el fortalecimiento de las organizaciones locales y su articulación con actores gubernamentales y otros externos (Montenegro y Aldo, 2012: 7), en las comunidades Huilliche de la costa de la Provincia de Osorno y las comunidades Pewenche en la Cordillera de Los Andes. Estas modalidades, además de garantizar la participación democrática ciudadana, refuerzan en el ámbito local las políticas para el desarrollo sostenible del territorio, en particular, y de la nación, en lo general.

\section{II.10 América Central y República Dominicana}

La Oficina Nacional de Planificación (ONAPLAN) de la Presidencia de República Dominicana, fue fundada el 22 de noviembre de 1965, mediante la ley 55 , aunque sus orígenes datan del año 1929, y en enero de 2007, fue promulgada como Subsecretaría de Planificación, con una Dirección General de Ordenamiento y Desarrollo Territorial (ONAPLAN, 2014). En el artículo 194 de la Constitución de República Dominicana, se plantea el Plan de Ordenamiento Territorial.

Actualmente, la colaboración regional propiciada por la Secretaría de la Integración Social Centroamericana (SISCA) ha fortalecido el proceso de planificación y ordenamiento territorial de los países de América Central y República Dominicana, lo que posibilita el intercambio de conocimientos y la reflexión en torno de la gestión del riesgo en los asentamientos humanos (SISCA, 2014); estudios emprendidos durante 2009 y 2012 con el apoyo de la Cooperación Internacional Alemana (GIZ) permiten o permitieron establecer un balance sobre el ordenamiento territorial en esta región (FerRufino, 2014). Según este especialista, los procesos de ordenamiento territorial en esta región presentan varios enfoques: (a) urbanístico-metropolitano, prevalente en los países más urbanizados, como Panamá y El Salvador; (b) planificación del desarrollo, en Costa Rica, existente desde los años setenta; (c) prevalencia hacia los riesgos ambientales, en los países que han sufrido grandes desastres, como Honduras, Nicaragua y El Salvador; y (d) la condicionante de la organización institucional reflejada en diversas estructuras institucionales de ordenamiento territorial, aunque la persistencia del pensamiento urbanístico no permite la identificación clara entre lo territorial, lo municipal y lo local, sobre todo en El Salvador, Costa Rica y municipios de Gua- 
temala. En Panamá existe la "Ley General del Ambiente", no 41 del año 1998. No obstante, estas realidades del contexto centroamericano y dominicano expresan la voluntad política de los gobiernos y la claridad institucional en el abordaje de la ordenación del territorio, como fórmula eficaz de la gestión territorial, como soporte para el necesario despegue económico, plasmado en las estrategias nacionales de desarrollo.

\section{HISTORIA DEL ORDENAMIENTO TERRITORIAL EN MÉXICO: INSTITUCIONALIDAD, LEGISLACIÓN, EDUCACIÓN UNIVER- SITARIA Y POSICIÓN ACADÉMICA}

\section{III.1 Presencia del ordenamiento territorial en el contexto institucional mexicano}

La planeación del desarrollo y la planeación urbana comienzan con la Ley sobre Planeación General de la República (ESTADOS UNIDOS MEXICANOS, 1930), cuando surgía la industrialización en el país (SÁNCHEZ, 2011: 1), y bajo el significado de la misma, se elaboran los primeros planes sexenales de la nación. No obstante, ya en la Constitución Política de los Estados Unidos Mexicanos del año 1917, "estuvo la redefinición de las leyes y reglamentos en cuanto a la tenencia de la tierra, el papel rector del Estado en la conducción de los asuntos económicos y sociales, así como, en la organización del espacio geográfico mexicano" (GARCíA, 2010: 103).

En el período comprendido entre los años 1947 y 1960, se inicia la aplicación de estrategias de desarrollo regional por medio de las Comisiones de Cuencas Hidrológicas, que incorporan el enfoque ecológico en la regulación territorial (SÁnchez y Palacio, 2004: 78).

Las primeras evidencias de una naciente conciencia de planeación territorial en México, comienzan en el año 1976, con la promulgación de la Ley General de Asentamientos Humanos (ESTADOS UNIDOS MEXICANOS, 1976), actualizada y derogada el 21 de julio de 1993 (ESTADOS UNIDOS MEXICANOS, 1993). Esta ley integra los aspectos ambientales del desarrollo con la planeación territorial (PALACio et al., 2009), y determina la creación de la Secretaría de Asentamientos Humanos y Obras Públicas (SAHOP) en el año 1976, la cual funciona bajo esta denominación hasta el año 1982, cuando el 29 de diciembre es propuesta como Secretaría de Desarrollo Urbano y Ecología (SEDUE), cuyas funciones 
culminan en el año 1992, para dar origen a la actual Secretaría de Desarrollo Social (SEDESOL).

En el seno de la SAHOP se establece en 1978, la Dirección General de Ecología Urbana, la cual acometió y supervisó la elaboración de los denominados Ecoplanes (1978-1981), dirigidos a evaluar objetivos urbanísticos y ecológicos en diferentes niveles espaciales, desde lo regional hasta lo municipal, así como en asentamientos humanos de carácter local. Según Azuela (2007: 15), "los ecoplanes eran instrumentos sin duda novedosos no sólo porque eran portadores de una mirada ambiental sumamente amplia, sino también porque traían consigo la incorporación de una nueva perspectiva disciplinaria a la planeación: la de la geografía". Unos años más tarde, el desarrollo de los sistemas de información geográfica, no sólo revivieron la esencia trascendental de la geografía en las esferas de la actividad humana, como ciencia del espacio, sino que abrieron las puertas de la "era digital" a los procesos de ordenación del territorio, y permitieron procesar grandes volúmenes de información, datos y cartografía automatizada. Este avance tecnológico contribuyó de manera notable a la resolución de las problemáticas complejas y a su representación espacial sintética, a incrementar los niveles de precisión temática en el territorio, y a la reducción de los tiempos de ejecución de las investigaciones. En México, esta nueva herramienta de "raíces geográficas", facilitó la realización de un gran número de proyectos de ordenamientos territoriales estatales bajo la supervisión de la SEDESOL, y de ordenamientos ecológicos territoriales (General del Territorio, regionales, municipales y marinos), bajo las normas jurídicas de la Ley General del Equilibrio Ecológico y la Protección al Ambiente -LGEEPA-, de la Secretaría de Recursos Naturales y Medio Ambiente (SEMARNAT).

Después de 1982, se establece la Subsecretaría de Ecología dentro de la SEDUE, con las funciones del control de las áreas naturales protegidas, el ordenamiento ecológico y la evaluación del impacto ambiental. Ya en 1993, al modificarse la Ley General de Asentamientos Humanos del año 1976, se establecen los cimientos del ordenamiento territorial de los asentamientos humanos y del desarrollo urbano de los centros de población (INE-SEMARNAP, 2000). En la actualidad, convergen tres regímenes jurídicos aplicables a la ordenación del territorio: la Ley General de Asentamientos Humanos (ESTADOS UNIDOS MEXICANOS, 1993), la Ley General del Equilibrio Ecológico y la Protección al Ambiente - LGEEPA (ESTADOS UNIDOS MEXICANOS, 1988) y la Ley de Planeación (ESTADOS UNIDOS MEXICANOS, 1983), esta última derogó la Ley sobre Planeación General de la República de 1930. 
A partir del Plan Nacional de Desarrollo (2000-2006), proyectado hacia la planeación territorial y el desarrollo sustentable en México, la SEDESOL, coordinadamente con la SEMARNAT, el Consejo Nacional de Población de la Secretaría de Gobernación (CONAPO-SG) y el Instituto Nacional de Estadística y Geografía (INEGI) se enfocaron al fortalecimiento de la planeación territorial, a niveles estatal y mesorregional, contando con el asesoramiento metodológico del Instituto de Geografía de la Universidad Nacional Autónoma de México (IGgUNAM). Para ello, se elaboraron dos generaciones de guías metodológicas, la primera en el año 2000, y la segunda, en el año 2005, que fueron aplicadas a los Programas Estatales de Ordenamiento Territorial (PEOTs) y al caso de la mesorregión Sur-Sureste del país, emprendidos entre los años 2000 al 2006. Todo este esfuerzo determinó la ejecución de los PEOTs en 28 entidades de las 32 de la Federación, incluido el Distrito Federal.

Al mismo tiempo, en México se elaboran los Planes de Ordenamiento Ecológico Territorial (POETs), bajo el marco jurídico de la LGEEPA (ESTADOS UNIDOS MEXICANOS, 1988) y la supervisión de la SEMARNAT, lo que constituye una visión dicotómica de un mismo proceso - la ordenación territorial. Realmente, el marco legal del ordenamiento descansa en la LGEEPA, y la existencia de dos visiones de ordenación territorial radica en la propia esencia de dos secretarías, como la SEDESOL, que implementa sus políticas sociales, y la SEMARNAT, que traza las políticas ambientales sobre el territorio nacional. En el caso de la SEMARNAT y de los POETs, se privilegia la protección y preservación del patrimonio natural, mientras en el caso de SEDESOL y de los PEOTs, se prioriza la población y sus asentamientos, así como el desarrollo económico. Esta fragmentación de intereses en el territorio ha sido fuente de innumerables conflictos intersectoriales, que reflejan la lucha entre el "conservacionismo", en ocasiones a ultranza, y el "productivismo" sin limitaciones, dentro de un mismo territorio respectivamente. Una de las desventajas de esta dualidad de enfoques es "la existencia de dos instrumentos de política territorial, el OT y el OE, en lugar de uno solo y los problemas de coordinación y comunicación institucional derivados de esta situación" (SÁnchez-SAlazAr et al. (2013: 750).

Por otra parte, esta realidad de desgaste de esfuerzos y de recursos financieros, bajo una actuación de duplicidad sectorial hacia la organización del territorio, exige en el corto plazo una revisión filosófica del proceso de planeación territorial en México, que conlleve a una visión integral y armónica, a nivel de la Administración Pública Federal, pues independientemente de las misiones y ordenanzas gubernamentales de cada una de las secretarías, el ordenamiento del territorio es un problema complejo, multidisciplinario y de consenso participativo entre los actores gubernamentales, académicos, gremiales, institucionales am- 
bientales y sociales, y el territorio, como objeto de ordenación, se caracteriza por su unicidad, singularidad e irrepetibilidad.

Un aspecto de gran significado para la gestión ambiental y el ordenamiento territorial en México, es la existencia de la Procuraduría Federal de Protección al Ambiente, creada el 4 de junio de 1992, la Procuraduría Ambiental y del Ordenamiento Territorial del Distrito Federal, establecida el 24 de abril de 2001 y otras procuradurías estatales, como la de Guanajuato. Estas instituciones están enfocadas a la violación, incumplimientos o falta de aplicación en las materias antes mencionadas.

En general, según GARCía (2010: 120), la evolución de la planeación en México puede dividirse en las direcciones y períodos siguientes: planeación económica, a partir de la década de los años 30; planeación regional, desde los años 40; planeación urbana y planeación ambiental, desde los años 80; y ordenamiento territorial, a partir de los años 90 hasta el presente.

\section{III.2 El ordenamiento territorial en las Universidades y la Academia}

Según Palacio (2011: 107), “el número de programas en Geografía en universidades de América Latina se ha incrementado de manera significativa en los últimos años. Durante la última década aparecieron 56 nuevos programas (licenciatura, maestría o doctorado)", atribuyendo las razones de dicho auge geográfico "...con la percepción que la sociedad tiene acerca de la Geografía y su importancia y presencia en asuntos cotidianos, el desarrollo y diseminación de herramientas tecnológicas para el manejo de información geográfica y la demanda de geógrafos en el mercado laboral". Indiscutiblemente, la esencia holística de la geografía per se, el desarrollo y direcciones de especialización, sobre todo a partir de la década de los años setenta, el surgimiento de la era aeroespacial con la percepción remota, los sistemas de información geográfica y el geoposicionamiento global, han propiciado el desarrollo del análisis espacial y, por ende, fortalecido la presencia del geógrafo en el contexto de la planeación territorial y de la gestión ambiental, ambas direcciones convergentes en los objetivos y alcances del ordenamiento territorial.

En México, son varias las universidades que poseen carreras universitarias y estudios de posgrado relacionados con enfoque territorial, a nivel regional (SÁnchez-Salazar y Hernández-Santana, 2011), entre las principales: (a) Universidad de Guadalajara, Jalisco: Licenciaturas (Geografía, Urbanística y Medio Ambiente e Ingeniería en Recursos Naturales y Agropecuarios); Maestrías (Desarrollo Local y Territorio, Políticas Públicas de Gobiernos Locales, Gestión 
y Desarrollo Social, Urbanismo y Desarrollo, Ciencias en Ecología y Gestión Integrada de Costas y Océanos, Ciencias en Manejo de Recursos Naturales, Ciencias en Biosistemática y Manejo de Recursos Naturales y Agrícolas); Doctorados (Ciudad, Territorio y Sustentabilidad, Ciencias en Biosistemática y Manejo de Recursos Naturales y Agrícolas); (b) Universidad Autónoma de Guadalajara, Jalisco: Especialidades (Urbanismo y Diseño de Vivienda Urbana); (c) Universidad Nacional Autónoma de México, campus Michoacán: Licenciaturas (Ciencias Ambientales); Maestrías (Geografía - Manejo Integrado del Paisaje); (d) Universidad Autónoma de San Luis Potosí, San Luis Potosí: Licenciaturas (Geografía, Diseño Urbano y del Paisaje); Maestría y Doctorado (Ciencias Ambientales); (e) Universidad Autónoma de Aguascalientes, Aguascalientes: Licenciaturas (Urbanismo, Ciencias Ambientales); (f) Universidad Autónoma de Querétaro, Querétaro: Licenciatura (Geografía Ambiental); Maestrías (Gestión Integrada de Cuencas, Recursos Bióticos); Doctorado (Recursos Bióticos); Especialidades (Gestión para el Desarrollo Comunitario); (g) Universidad de Guanajuato, Guanajuato: Campus León y Celaya: Licenciatura (Desarrollo Regional); Campus Guanajuato: Maestría (Planeamiento Urbano Regional); (h) Universidad Autónoma del Estado de México, Toluca: Licenciaturas (Geografía, Ciencias Ambientales, otras); Especialidades (Estudios de Población con enfoque regional); Maestrías (Estudios Urbanos y Regionales, Análisis Espacial y Geoinformática, Ciencias Ambientales, Ciencias Agropecuarias y Recursos Naturales, Ciencias del Agua); Doctorados (Arquitectura, Diseño y Urbanismo, Ciencias Naturales, Ciencias Agropecuarias y Desarrollo Rural). En la Universidad Nacional Autónoma de México, campus Distrito Federal, las carreras, especialidades y posgrados, que ocupan esta temática son innumerables, encabezándolas el Instituto de Geografía y su Posgrado en Geografía (SÁnchez-Salazar y Hernández-Santana, 2011).

Ante la creación del campus UNAM de la Escuela Nacional de Estudios Superiores, Unidad León, estado de Guanajuato, y a partir de un diagnóstico de las necesidades regionales en relación con licenciaturas impartidas en el territorio desde una perspectiva multifactorial, durante los años 2010 y 2011, el Instituto de Geografía (I., Alcántara-Ayala, M. T., Sánchez-Salazar, J. R., Hernández-Santana, M., Suárez-Lastra, O., Oropeza-Orozco y J. A., Quintero-Pérez) de la UNAM, consideró la pertinencia de elaborar una propuesta de Licenciatura en Gestión Integral del Territorio. Esta licenciatura se diseñó en cuatro años, de 32 semanas cada uno y 380 créditos aproximadamente, y sus objetivos son formar profesionales en el análisis, la planeación y la gestión territorial con una visión integral y multidisciplinaria, capaces de identificar problemas derivados de la interacción entre los fenómenos y procesos naturales, sociales, económicos, urbano-regionales y político-administrativos a diferentes escalas. El propósito cardinal es propo- 
ner alternativas de solución a problemáticas territoriales desde una perspectiva de desarrollo sostenible. Actualmente, la Escuela Nacional de Educación Superior (ENES) formula la creación de la Licenciatura en Desarrollo Territorial en cuatro años, con 60 materias, en modalidades de obligatoria y opcional, y un cuarto año con tres áreas de profundización (SuÁrez PaniaguA, común. pers., 2014).

Desde otro ángulo, el interés por la temática de la ordenación del territorio dentro del ámbito académico mexicano ha ocupado numerosos proyectos en coordinación con SEDESOL, SEMARNAT, INEGI y organizaciones no gubernamentales, y ha encontrado repercusión en el desarrollo de varios congresos bianuales, contando con una amplia participación de geógrafos y de especialistas afines al análisis territorial: I Congreso Internacional de Ordenación del Territorio, México, D. F., 2001; II Congreso Internacional de Ordenación del Territorio, Toluca, 2003; III Congreso Internacional de Ordenación del Territorio, Guadalajara, 2005; IV Congreso Internacional de Ordenamiento Territorial, San Luis Potosí, 2007; V Congreso Internacional de Ordenamiento Ecológico y Territorial, Morelia, 2009; VI Congreso Internacional de Ordenamiento Territorial y Ecológico, Ensenada, 2011; VII Congreso Internacional de Ordenamiento Ecológico y Territorial, Cuernavaca, 2013; y VIII Congreso Internacional de Ordenamiento Territorial y Ecológico, Cusco, Perú, 2014.

Derivados de estos eventos, se publicaron varios libros sobre ordenación del territorio: "El ordenamiento territorial: Perspectivas Internacionales" (2008), "Ordenamiento territorial y participación social: problemas y posibilidades" (2011) y, recientemente, "La Política de Ordenamiento Territorial en México: de la Teoría a la Práctica" (2013).

\section{ORDENAMIENTO ECOLÓGICO TERRITORIAL: ESCALAS Y ALCANCES}

Transcurrido un cuarto de siglo de la promulgación de la LGEEPA, en 1988, si bien no se ha avanzado todo lo deseado en materia de ordenamientos ecológicos territoriales (OETs) decretados, se aprecia un gran impulso si se compara con lo argumentado por Azuela (2007: 19-20), cuando en el año 2004, sólo existían 27 proyectos de OET decretados. Hasta septiembre de 2013 (SEMARNAT, 2014), se han decretado el Programa de Ordenamiento Ecológico General del Territorio -POEGT- (12 de septiembre de 2012), el OET Marino del Golfo de California, y el Marino Regional del Golfo de México y Mar Caribe, 40 OETs regionales y 60 OETs locales, para un total de 103 OETs, tomando en consideración que el POEGT es nacional y los dos OETs marinos ocupan vastas cuencas 
marinas. Si observamos la superficie cartográfica ocupada por los ordenamientos regionales y locales decretados, éstos abarcan más del $50 \%$ del territorio nacional. Por ello y por la voluntad política gubernamental y el interés de los diferentes actores que intervienen en estos procesos, existe y prevalece un creciente interés por el ordenamiento territorial en México (Azuela, 2007: 20).

\section{IV.1 Programa de Ordenamiento Ecológico General del Territorio - POEGT}

El Capítulo IV de la LGEEPA (ESTADOS UNIDOS MEXICANOS, 1988) aborda los instrumentos de la planeación ambiental en México, y señala en su Sección II "Ordenamiento Ecológico del Territorio", las distintas modalidades y alcances de cada instrumento. En este sentido, el POEGT "será formulado por la Secretaría (en este caso la SEMARNAT), en el marco del Sistema Nacional de Planeación Democrática", teniendo como objeto "la regionalización ecológica del territorio nacional"..., "a partir del diagnóstico de las características, disponibilidad y demanda de los recursos naturales, así como de las actividades productivas que en ellas se desarrollen y, de la ubicación y situación de los asentamientos humanos existentes", e incorpora "los lineamientos y estrategias ecológicas para la preservación, protección, restauración y aprovechamiento sustentable de los recursos naturales, así como para la localización de actividades productivas y de los asentamientos humanos".

Desde la promulgación de la LGEEPA fueron tres los intentos sexenales para la ejecución y formulación del POEGT:

(a) Sexenio 1989-1994: la SEMARNAT traza los primeros pasos para emprender el propósito de caracterizar y diagnosticar la oferta y el estado general de los recursos naturales del país, conocer la demanda sectorial de los mismos, analizar los niveles de conflicto y de sinergia entre los sectores, para en función de las relaciones de potencialidad y de compatibilidad de uso, proponer el modelo de ocupación del territorio nacional. Como toda etapa inicial, sin antecedentes conceptuales ni metodológicos, con débiles vínculos entre el sector ambiental y los restantes sectores de la Administración Pública Federal (APF), limitada información primaria en bases de datos, notable ausencia de los formatos digitales necesarios para la automatización, escasa representación cartográfica de la gran mayoría de las variables básicas para la planeación, entre otros aspectos, fue abortado este primer intento.

(b) Sexenio 2000-2006: la Secretaría publica el reglamento de la LGEEPA, en materia de ordenamiento ecológico (SEMARNAT, 2003), pero desafortunadamente no se concretaron los acuerdos necesarios entre los sectores, fundamen- 
talmente entre SEDESOL y SEMARNAT, secretarías que impulsaban paralelamente dos visiones de ordenamiento del territorio: los Programas Estatales de Ordenamiento Territorial (PEOTs) y los Programas de Ordenamiento Ecológico Territorial (POETs) respectivamente. De cierta manera, una vez concluidos los PEOTs y los proyectos de gran visión, en los años 2005 y 2006, cierran este sexenio, y la SEDESOL orientó sus acciones, en lo fundamental, hacia el desarrollo regional.

(c) Sexenio 2006-2012: luego de casi dos décadas, se establece el Grupo de Trabajo Intersecretarial (GTI), con la presencia de representantes de las secretarías de la APF, forjándose una conciencia intersecretarial sobre los principios, conceptos, métodos y alcances de la planeación general del territorio nacional. Además, la experiencia acumulada en los dos intentos anteriores, unida a los resultados de diversos ordenamientos ecológicos regionales, posibilitó alcanzar condiciones de madurez metodológica, jurídica y sectorial para la ejecución y formulación de un modelo de ocupación, como orientación estratégica de las políticas sectoriales de la APF, de acuerdo con las políticas ambientales requeridas en cada región del territorio nacional.

Entre los años 2008 y 2011, el POEGT fue financiado por las autoridades de la SEMARNAT y del Instituto Nacional de Ecología (INE, hoy Instituto Nacional de Ecología y Cambio Climático-INECC), y ejecutado por un equipo de 36 investigadores y técnicos del Instituto de Geografía, del Centro de Investigaciones en Geografía Ambiental y del Centro Regional de Investigaciones Multidisciplinarias de la Universidad Nacional Autónoma de México (HernándezSANTANA et al., 2013a, 2013b), así como, por especialistas y consultores de la Universidad Autónoma de Querétaro, focalizados estos últimos, en la evaluación de las políticas públicas (ONGAY y ZorRILLA, 2008a) y de los requerimientos ambientales para la aptitud sectorial de cada uno de los sectores del gobierno federal de México (OngaY y Zorrilla, 2008b). Además, contó con la supervisión de directivos y especialistas de la SEMARNAT y del INE, y de facilitadores del proceso técnico participativo en los talleres regionales celebrados en las ciudades de Guadalajara, Distrito Federal y Tuxtla Gutiérrez, en 2009; y de Hermosillo, Monterrey, Guadalajara, Distrito Federal, Oaxaca y Mérida, como sedes de las grandes regiones del país, como Noroeste, Noreste, Occidente, Centro, Sur y Sureste respectivamente, en 2010; y dos consultas públicas nacionales en línea, en los años 2010 y 2011.

Para el análisis territorial nacional y la evaluación del estado medioambiental actual, se empleó la regionalización ambiental biofísica de LóPEZ-BLANCO (2008), integrada por 145 regiones, designadas como unidades de análisis te- 
rritorial. Esta visión geoecológica sintética de los paisajes físico-geográficos o unidades ambientales biofísicas, propia de la conceptualización geográfica, para designar las unidades de análisis territorial, fue un gran acierto en el contexto del POEGT, éste permitió analizar al medio ambiente como un sistema abierto de conformación histórica, como producto de las interacciones entre la naturaleza, la sociedad y su economía (BUCEK, 1983; ARCIA, 1994; MATEO y ORTIZ, 2001) y poder evaluar su estado con indicadores de degradación biofísica, modificación antrópica, situación socioeconómica y disponibilidad de recursos hídricos superficiales y subterráneos (Hernández-SANTANA et al., 2011; Bollo-MANENT et al., in press, 2014).

La evaluación de los 18 indicadores de la situación ambiental de cada una de las 145 unidades de análisis territorial, consideró el método matricial y los criterios de expertos, reunidos en tres grupos: (a) problemas de la gestión de los recursos naturales (uso de suelo, degradación de los suelos, degradación de la vegetación, degradación por desertificación), (b) modificación antrópica (longitud de carreteras, en km; superficie de zona urbana, en porcentaje; superficie de cuerpos de agua, en porcentaje; y densidad de población, en hab $/ \mathrm{km}^{2}$ ) y (c) situación socioeconómica (marginación social, índices medios de educación y de salud, hacinamiento y consolidación de la vivienda, capitalización industrial, tasa de dependencia económica municipal y trabajadores por actividades remuneradas por municipio). Con esta evaluación, el pronóstico de la etapa III contempló el análisis de conflictos y sinergias intersectoriales, la realización de talleres de consulta y validación, y la construcción de los escenarios contextual (2008), basado en la evaluación ecológica del medio ambiente y tendenciales (2012, 2023, 2033), a partir del intercambio entre expertos en talleres regionales (HERNÁNDEZ-SANTANA et al., 2011; Bollo et al., 2011; Bollo-Manent et al., in press, 2014).

Desde el punto de vista metodológico, la determinación de las áreas de atención prioritaria de un territorio permite identificar y clasificar aquellas con conflictos ambientales por actividades sectoriales antagónicas o aquellas que por sus características requieren de una atención ambiental inmediata. La evaluación de los conflictos intersectoriales fue realizada en múltiples talleres regionales y su sumatoria permitió establecer cinco categorías para los mismos (nulo a muy alto). A partir de dichas categorías de conflictos y del estado actual del medio ambiente de cada unidad ambiental biofísica, se establecieron las categorías de atención prioritaria en 5 niveles. El 0,90\% de la superficie del país presenta un nivel prioritario muy alto; el 6,76 \% un nivel alto; el 39,40 \% una atención media; un 21,81 $\%$ de baja atención; y el 31,14 \% no necesita de atención por el momento (BoLLO et al., 2013). 
De acuerdo con la LGEEPA, uno de los productos básicos es la regionalización ecológica, aspecto básico para cada una de las unidades ambientales biofísicas y para conocer su estado actual del medio ambiente, su política ambiental y el grado de atención prioritaria. Para el caso del POEGT, la regionalización ecológica (o ecólogo-productiva, dado que contempla la actividad multisectorial) se determinaron 80 regiones ecológicas, que después de un análisis de compatibilidad entre la aptitud y el interés sectorial en cada unidad ambiental biofísica, permitió la propuesta de 34 tipos de actividades rectoras del desarrollo, con 10 lineamientos ambientales generales, 44 estrategias ecológicas y 273 acciones de implementación (HERNÁNDEZ-SANTANA et al., 2013a, 2013b), todas sujetas a las decisiones del Grupo de Trabajo Intersectorial, como artesano del tejido territorial de la Federación (HeRnÁnDEZ-SANTANA, 2014: 3).

Los resultados básicos alcanzados en dicho proceso, primero de su tipo culminado en el país, permitió el decreto del POEGT, publicado en el Diario Oficial de la Federación, el 7 de septiembre de 2012. Este decreto es de "observancia obligatoria en todo el territorio nacional y vinculará las acciones y programas de la Administración Pública Federal y las entidades paraestatales en el marco del Sistema Nacional de Planeación Democrática" (ESTADOS UNIDOS MEXICANOS, 2012). Desde el año 2013 y hasta el presente, la SEMARNAT diseña un Sistema de Información Geográfica (SIGPOEGT), con las principales variables utilizadas en la primera edición del POEGT, que permitirá el análisis actualizado de cada una de las etapas del ordenamiento nacional: (I) Caracterización del sistema territorial, (II) Diagnóstico integrado del sistema territorial, (III) Pronóstico, de debate público participativo, (IV) Proposición del Modelo de Ordenamiento Ecológico General del Territorio (MOEGT), y (V) Implementación, con la finalidad de realizar evaluaciones periódicas y actualizaciones de este instrumento de planeación del territorio.

\section{IV.2 Programas de Ordenamiento Ecológico Marino}

En septiembre de 2013, ya estaban decretados los OETs Marino Golfo de California (2006) y Marino y Regional Golfo de México y Mar Caribe (2012) (SEMARNAT, 2014). En el segundo caso, el proceso de ordenamiento comenzó en el año 2007, participaron 10 secretarías de estado, dos empresas paraestatales (Petróleos Mexicanos - PEMEX, y Comisión Federal de Electricidad - CFE), el INEGI y el INAH (Instituto Nacional de Antropología e Historia), así como, los gobiernos de los seis estados de la República que conforman la región. Una de las características de estos programas es que incluyen desde la zona federal marítimo terrestre hasta el límite de la zona económica exclusiva, pero tomando en 
consideración los procesos terrestres que influyen en el dominio marino (ROSETE y Negrete, 2012: 305-306). Además, se han desarrollado nuevas aproximaciones para la incorporación de la gestión del riesgo, tanto en los ordenamientos antes señalados (Rosete et al., 2013: 12), como en la ciudad portuaria de Manzanillo, localizada en el Pacífico (Thомаs, 2013: 81).

Si bien ese ordenamiento ecológico marino representa un avance, en cuanto a lo conceptual y metodológico, es necesario seguir avanzando en la construcción de indicadores que faciliten la integración de los diferentes tipos de peligros y en la generación de estrategias concretas de adaptación al incremento de aquellos asociados al cambio global.

\section{IV.3 Programas Regionales de Ordenamiento Ecológico Territorial}

Desde los años noventa hasta 2014, se han decretado un total de 40 ordenamientos ecológicos territoriales de modalidad regional (SEMARNAT, 2014). Entre ellos se pueden citar, los estatales de Baja California, Durango, Jalisco, Colima, Guanajuato, México, Hidalgo, Distrito Federal, Tlaxcala, Tabasco, Yucatán, Querétaro, Michoacán y Chiapas; así como, de la gran cuenca petrolífera de Burgos, de áreas naturales protegidas (Región Mariposa Monarca, Valle de Bravo, Volcán Popocatepetl y su área de influencia, Región de Sian Ka'an en Quintana Roo, y otras), de grandes cuencas hidrográficas (Laguna de Cuyutlán, Río Tepalcatepec, Lago Cuitzeo, Río Tuxpan, Ríos Bobos y Solteros, Río Coatzacoalcos, Río Lagartero, Río Sabinal, Subcuenca Nevado Sur, y otras) y de zonas costeras de importancia turística (Corredor costero Tijuana-Ensenada, Costa Alegre, costero de Yucatán, Corredor Cancún-Tulum, Costero de Sonora, entre las principales). En los ordenamientos ecológicos territoriales, a nivel regional, un enfoque empleado con cierta frecuencia, es la adopción de las unidades de paisaje físico-geográfico (Bollo-Manent y Hernández-Santana, 2008: 8), como unidades de análisis territorial y de evaluación de la aptitud natural (potencialidades y limitaciones naturales) (Bollo et al., 2010: 192) y, finalmente, como unidades de gestión del ordenamiento ecológico.

\section{IV.4 Programas Locales de Ordenamiento Ecológico Territorial}

Dentro de los OETs locales, figuran los municipales y locales de especial interés. Hasta el presente, 60 de ellos han sido decretados, 50 de carácter municipal y el resto en zonas de características especiales, en general, como San Quintín, en Baja California; Cuatrociénegas, en Coahuila; zona costera de El Rosario, en Sinaloa; puerto de Lázaro Cárdenas, en Michoacán; la Costa Maya y la región 
Laguna de Bacalar, en Quintana Roo; la cuenca del Río Coapa y la subcuenca del Río Zanatenco, en Chiapas (SEMARNAT, 2014). A pesar de que en los OETs regionales quedan agrupados un número grande de municipios, dado que en México existen 2440 municipios y 16 delegaciones del Distrito Federal (INAFED, 2014), en esta modalidad de ordenamientos locales (municipales), aun se requiere de un sostenido esfuerzo en los próximos años.

\section{IV.5 Programas Comunitarios de Ordenamiento Ecológico Territorial}

De acuerdo con Negrete y Bocco (2003: 13), "el ordenamiento ecológico comunitario participativo implica la conjugación del conocimiento técnico con el tradicional, el manejo del territorio comunitario con el manejo del territorio regional...", es por ello, que en la planeación comunitaria de un territorio, LARA y Chapela (2006: 99) plantean algunas características básicas, como que la comunidad es la unidad de planeación; ocupando un territorio compartido por un grupo social o varios; que reconocen actores sociales internos y externos, que velan por el equilibrio de las decisiones; reforzando su cultura propia con nuevas prácticas de manejo de recursos naturales; y tomando el conocimiento empírico de sus integrantes para alcanzar propuestas de uso del suelo compatibles con la visión colectiva. Sobre estas bases, de manera general, es que en México se han realizado 287 ordenamientos comunitarios del territorio (fundamentalmente en los estados de Oaxaca, Michoacán, Guerrero, Chiapas y Jalisco), los que ocupan una superficie de 2679391 ha, cuyo tipo de tenencia predominante es el comunal y el ejidal (GonZÁLEz Ortiz, 2014).

En otra dirección de la planeación del territorio, el incremento de proyectos productivos, de alto impacto ambiental en regiones silvestres muy conservadas, como la Península de Baja California, ha obligado a establecer enfoques novedosos para la determinación de áreas prioritarias de geo-conservación, tomando como base la regionalización de los paisajes físico-geográficos y la distribución de la riqueza y el endemismo biótico (ZARAGOZA et al., 2013: 9, 21), revelándose mediante un análisis de vacíos de conservación, que entre el 24 y el 39 por ciento de la superficie de la Península no está protegida. Estos resultados, sin dudas, fortalecen los métodos y los criterios en el momento de presentar propuestas de política ambiental y de desarrollo de actividad sectorial en los modelos de ocupación del territorio y en los planes de su desarrollo regional. 


\section{VISIÓN DEMOCRÁTICA GUBERNAMENTAL Y PARTICIPA- CIÓN SOCIAL}

Uno de los pilares básicos para el éxito de cualquier empresa o propósito social es la participación democrática de todos sus ciudadanos, como expresión de soberanía plena para solucionar sus problemas políticos, económicos, sociales, ambientales y de planeación del desarrollo de su territorio, sin obviar, que una de las condiciones para el verdadero desarrollo del hombre y de su sociedad es el pleno ejercicio de su libertad, en su más vasto prisma de acciones. De acuerdo con la tipología de SERRA-VÁzquez (en RENTERÍA, 2011: 452), las manifestaciones más eficientes de la participación social son "(a) la reflexiva, con claridad de objetivos y actitud crítica, y con valores de solidaridad, respeto y apertura; y (b) la praxis creativa, con propuestas nuevas y coherentes, respeto, diálogo y consenso". En el caso mexicano, la reivindicación de los derechos de los ciudadanos para expresar sus intereses y preferencias múltiples es lo que ha conducido a la extensión y a la validación de las políticas participativas (OLIVos, 2014: 21), que han encontrado eco en la legislación y quehacer del ordenamiento ecológico territorial de la nación, a todos sus niveles espaciales y político-administrativos; aunque lamentablemente no siempre los coordinadores de estos procesos han sabido organizarlas adecuadamente o asimilar sus resultados en las decisiones finales para la propuesta de los modelos de ocupación territorial.

Estas cualidades están incorporadas en el reglamento de la LGEEPA, del año 2003, que establece que el ordenamiento ecológico territorial es un proceso de planeación, que exige la creación de un comité permanente, donde participen los diferentes actores (personas, organizaciones, grupos e instituciones de los sectores público, privado y social), para alcanzar consensos y velar por el desarrollo transparente del proceso, privilegiando la congruencia de planes, programas y acciones sectoriales en el área de estudio, así como, resolver los conflictos ambientales y promover el desarrollo sustentable (Rosete, 2006: 49). Una de las modalidades de la participación social y sectorial es la organización de talleres de planeación, regionales de debates y definiciones, y consultas públicas en línea, con el objetivo de recabar opiniones, criterios y, finalmente, acuerdos consensuados sobre los estudios técnicos de cada etapa, las tendencias del desarrollo territorial a diferentes plazos, el análisis de conflictos y sinergias intersectoriales y sociales, así como, proponer lineamientos y estrategias ambientales, que regulen las diferentes actividades sectoriales propuestas en el modelo de ocupación del territorio.

A manera de ejemplo, talleres de este tipo fueron desarrollados en el ordenamiento ecológico territorial, de carácter regional, de los municipios petroleros 
de la región V Norte del estado de Chiapas (RojAs, 2010: 45), donde 16 grupos de trabajo identificaron y ponderaron problemáticas económicas, sociales y ambientales con la participación gubernamental, gremial, social y ciudadana, que permitieron, mediante el empleo de cartografía e imágenes satelitales, con simbología apropiada para el entendimiento público, identificar áreas de introducción de plagas, zonas de actividades ilícitas en la ganadería, localización de vertederos ilegales de residuales sólidos, que atentan contra la calidad medioambiental y proponer actividades de uso del suelo, acordes con las potencialidades de sus paisajes físico-geográficos.

No obstante, en otros ordenamientos ecológicos territoriales, como en la zona metropolitana de la ciudad de Guadalajara, en Jalisco, no siempre ha funcionado eficientemente este principio participativo de la ciudadanía (RoDRíGUEZ y Saavedra, 2011: 268), por lo que estos autores plantean, que "quizás la democracia representativa es la manera más económica y factible para participar en procesos de planeación", pero "el asunto es elegir actores sociales e individuales realmente representativos de la sociedad, que además de ser conocedores de la problemática que enfrenta el territorio, tengan los suficientes conocimientos técnicos para tomar las mejores decisiones en relación con la problemática espacial y aportar las soluciones más pertinentes". Esto será una tarea de perfeccionamiento permanente dentro de las acciones del ordenamiento ecológico del país, que deberá nutrirse de las experiencias acumuladas, acertadas o no, en el afán de conducir con plena participación social estos procesos, desde sus inicios, e integrar sus consensos en la formulación de los planes, anulando todo tipo de intervención por parte de intereses grupales de círculos de poder, totalmente incompatibles con la real democracia participativa.

\section{CONCLUSIONES: UNA MIRADA A LA VIABILIDAD FUTURA}

Resultan indiscutibles los esfuerzos institucionales, jurídicos, académicos, docentes, participativos sociales y financieros gubernamentales emprendidos por México en los propósitos de alcanzar una adecuada planeación territorial de las actividades sectoriales de la economía, sobre todo en los últimos cinco lustros, despertando una conciencia ciudadana, no sólo en la gestión ambiental, sino en la necesidad imperiosa de proyectar el desarrollo sostenible de la nación sobre bases rigurosas de ordenación de su territorio, y a todos los niveles de la administración gubernamental. No obstante esta destacada actuación y notable empeño, existen aún muchas dificultades que atentan contra la optimización de esta empresa nacional. 
La persistencia de la dualidad de enfoques en las pretensiones de organizar el territorio, emprendidos por la SEDESOL y la SEMARNAT, desde el año 1988, requiere de un profundo análisis filosófico, metodológico y de adecuación jurídica, que faciliten el desarrollo de un solo, pero robusto instrumento de ordenación territorial, donde converjan todos los intereses sectoriales, se faciliten más las sinergias que los conflictos, donde la coordinación de todos los actores sociales prevalezca sobre cualquier tipo de interés ajeno al inteligente derrotero de la sociedad en aras de aprovechar, de manera sostenible, sus recursos naturales, sobre una plataforma acertada y consensuada de planeación del territorio. Semejante debate teórico tendrá tropiezos, pero será la única vía para alcanzar una visión única sobre un fenómeno único - el ordenamiento del territorio.

El soporte educativo es vital para el adecuado desarrollo de cualquier actividad humana. Uno de los principales obstáculos que aún persisten, es la ausencia de una educación integral sobre el significado del ordenamiento territorial en la primera y la segunda enseñanzas del sistema nacional; en la enseñanza superior existen lánguidos avances, pues aunque la temática es abordada de manera diferenciada en algunas carreras universitarias, adolece de una óptima visión holística. Gran parte de los logros en esta esfera, se deben a la transferencia cognoscitiva de la vanguardia académica del país, a la experiencia de instituciones y consultorías ambientales, y a la difusión gubernamental, periodística y comunitaria, pero todo ello no ha sido suficiente para crear una sólida y clara conciencia sobre la organización y la gestión del territorio. Paralelamente a ello, debe acrisolarse, sobre todo en las diferentes instancias sectoriales de la economía, el desarrollo de modernos soportes tecnológicos para el procesamiento automatizado de la información estadística y la geográfica espacial, y de una extensiva cultura cartográfica, como lenguaje básico para la interpretación y la toma de las decisiones, no sólo sectoriales, sino además ciudadanas.

Precisamente, al no existir un arraigo por enfoques holísticos en el ordenamiento, debido a la carencia de una formación integral, cada especialista imprime el sesgo de su disciplina, generando descompensaciones internas en las etapas de caracterización y diagnóstico. A futuro, la autoridad de la planeación del territorio deberá velar por la conformación balanceada y equilibrada de equipos de académicos y técnicos, en función de los perfiles necesarios; obviando, por supuesto, la azarosa composición de especialistas, decidida por cuestiones ajenas a las propias esencia y necesidad del ordenamiento. Esta es una actividad multidisciplinaria y los equipos ejecutores deben cumplir también dicha cualidad.

Un común denominador en los proyectos de ordenamiento ecológico territorial desarrollados en el país, es la falta de correspondencia entre los tiempos 
políticos de solicitud y ejecución, con los tiempos realmente necesarios, desde el punto de vista técnico. El cumplimiento de esta premisa constituye un factor esencial para el rigor y la calidad académica de los estudios, que se traducen además en su acertada implementación. En este último proceso es muy conveniente, que el equipo ejecutor, conjuntamente con el Comité de Ordenamiento, sean los encargados de aplicar los acuerdos consensuados e implemente la aplicación del modelo de ocupación propuesto.

En México, con el establecimiento del Sistema Nacional de Planeación Democrática, fundamentado en la Ley de Planeación, se ha logrado consolidar la participación gubernamental y académica, con la gremial y social, en los procesos de planeación y ordenamiento del territorio, con mayor dinamismo en los programas locales y comunitarios, pero consistente en los programas regionales y en el general del territorio, en este último con innumerables talleres y dos consultas públicas. Este aspecto debe ser un reto permanente del país, contar siempre con los principios de la democracia participativa consciente y/o con la representativa idónea, y con la voz del consenso por mayoría.

El seguimiento y la continuidad de las decisiones contempladas en los programas de ordenamiento territorial, muchas veces se interrumpen con los períodos electorales y cambios de ejecutivos y funcionarios cada tres años, fundamentalmente a nivel municipal, lo que genera serios problemas en su adecuada implementación. Los programas de ordenamiento deben considerarse como "documentos bíblicos", sólo merecedores de actualizaciones periódicas, por parte de todos los actores sociales.

Uno de los problemas que anualmente afrontan el gobierno y la sociedad mexicana, son las pérdidas de vidas humanas y los daños económicos ocasionados por eventos hidrometeorológicos extremos, que determinan una permanente indemnización, a partir del Fondo de Desastres Naturales (FONDEN), con una considerable corrosión al producto interno bruto de la nación. Los programas de ordenamiento territorial deben asimilar, aún más, los planes y acciones de la gestión del riesgo, tanto en lo preventivo como en lo correctivo, sobre todo si se toma en consideración, que gran parte de los desastres naturales son el resultado de una elevada vulnerabilidad física y social, inducidas por la vergonzosa y lamentable ubicación de asentamientos en zonas marginales, a merced de la dinámica de los procesos intrínsecos a las amenazas naturales, como huracanes y sus inundaciones, procesos de remoción en masa en laderas, entre los más recurrentes. Ante el ascenso del nivel medio del mar, la casi generalizada tendencia a la subsidencia de las costas tropicales húmedas del Golfo de México y otros fenómenos naturales y antrópicos, resulta de inmediata atención, el proceso de reordenamiento del 
territorio costero. En los últimos años, ciudades como Villahermosa, Minatitlán, Coatzacoalcos, Tlacotalpan y Veracruz han desafiado los emblemáticos paisajes acuáticos de Venecia.

Este aspecto es uno de los mayores retos globales contemporáneos, pero sobre todo en México, debido a la alta concentración de su población, de sus actividades portuarias, comerciales, turísticas y de recreación, extendidas por miles de kilómetros, a lo largo de sus zonas costeras. No sería exagerado clamar por un SOS a las costas mexicanas del Golfo y a algunas del Pacífico, como en Guerrero y Chiapas.

En México, donde sobresale una amplia gama de comunidades indígenas, hablantes de 68 agrupaciones lingüísticas, oficialmente reconocidas (INALI, 2008), que conforman al país como una nación pluricultural, es ética y metodológicamente imprescindible el respeto y la asimilación de las culturas y conocimientos de dichas comunidades en los programas de ordenamiento, en general, y en particular, en los comunitarios.

Por último, aunque los programas de ordenamiento territorial poseen diferentes alcances y niveles de precisión, unos a escala detallada y analíticos, y otros a escala pequeña y sintéticos, resulta ineludible el engarce compatible entre sus niveles de propuesta de ocupación, para que las visiones estratégicas de la nación, se correspondan con las operativas, estas últimas plasmadas en los ordenamientos ecológicos regionales y locales.

\section{BIBLIOGRAFÍA}

Araque, I., Yahaira, T. (2006): «Programa de la Unidad Curricular Ordenamiento Territorial Ambiental». En línea: http://www.ordenamiento_territorialambiental. VIsemestre.doc.pdf. Consultado el 2 de octubre de 2014.

Arcia Rodríguez, M. (1994): «La Geografía del Medio Ambiente». Facultad de Planeación Urbana y Regional. Universidad Autónoma del Estado de México, Toluca.

Azpur, J. (2011): «Análisis de la legislación sobre planificación territorial en el Perú». Grupo Propuesta Ciudadana y Revenue Watch Institute. En línea: http://www2.congreso.gob.pe/sicr/cendocbib/con4_uibd.nsf/9B19205C8BD7EB2E05257B7C007856 FF/\$FILE/Peru.pdf. Consultado el 24 de febrero de 2014.

Azuela De La Cueva, A. (2007): «Las estrategias y las expectativas. Breve reconstrucción histórica del ordenamiento ecológico del territorio en México» en El ordenamiento ecológico del territorio en México: génesis y perspectivas (Azuela De LA Cueva, A., ed.). SEMARNAT, México, 4-34. 
Bollo-Manent, M., Hernández-Santana, J. R. (2008): «Paisajes físico-geográficos del Noroeste del Estado de Chiapas, México». Investigaciones Geográficas, nº 66, 7-24.

Bollo-Manent, M., Hernández-Santana, J. R., Méndez-Linares, A. P. (2010): «Evaluación de potencialidades naturales en el ordenamiento ecológico territorial: Noroeste del Estado de Chiapas, México». Boletín de la Asociación Geógrafos Españoles n 53,189-216.

Bollo-Manent, M., Hernández-Santana, J. R., Méndez-Linares, A. P., Figueroa-Mah ENG, J. M. (2011): «La Geoecología en el ordenamiento ecológico territorial. Estudio de caso» en Ordenamiento territorial y participación social: problemas y posibilidades (Aguilar Robledo, M., Delgado López, E., Vázquez Solís V., Reyes Pérez, O., eds.). México, D. F., CIGA (UNAM)-INE (SEMARNAT), 203-240.

Bollo-Manent, M., Hernández-Santana, J. R., Méndez-Linares A. P. (2013): «Áreas de atención prioritaria en México: una óptica medioambiental». Journal of Latin American Geography. Vol. 12 (n 2), 61-82.

Bollo-Manent, M., Hernández-Santana, J. R., Méndez-Linares, A. P. (in press, 2014): «The state of the environment in Mexico». Central European Journal of Geosciences.

BuceK, A. (1983): «Problemática de las investigaciones geográficas del medio ambiente». Studia Geographica n ${ }^{\circ} 86,17-25$.

CABrera, Y. (2012): «Antecedentes del proceso de ordenamiento territorial ambiental del espacio geográfico venezolano». En línea: http://yolycabrera.blogspot.mx. Consultado el 4 de octubre de 2014.

CÁrdenas, O. (2014): «Un modelo de ordenamiento ambiental para enfrentar los problemas ambientales del territorio cubano». En línea: http://www.monografias.com/ trabajos $81 /$ modelo-ordenamiento-ambiental/modelo-ordenamiento-ambiental.shtml. Consultado el 16 de febrero de 2014.

CEPAL (2011): «Plan regional de ordenamiento territorial: Contenido y procedimientos». Chile.

Colonnello, G., SAlas-Dueñas, D. (2004): «El ordenamiento territorial y los humedales» en El Agua en Iberoamérica. Calidad del agua y manejo de ecosistemas acuáticos (Cirelli, Fernández, Di Risio, eds.). Buenos Aires.

Cox, M. (2008): «Desarrollo Territorial en Chile: Instrumentos del Estado». Documento de Trabajo $N^{\circ}$ 3. Programa Dinámicas Territoriales Rurales. Rimisp, Santiago, Chile.

De Cássia Gregório De Andrade, R. (2010): «Política nacional de ordenamiento territorial: el caso de Brasil». Espacio y Desarrollo n ${ }^{\circ} 22,119-134$.

ESTADOS UNIDOS MEXICANOS (1930): «Ley sobre Planeación General de la República». Diario Oficial de la Federación, 12 de julio de 1930, México, D. F.

ESTADOS UNIDOS MEXICANOS (1976): «Ley General de Asentamientos Humanos». Diario Oficial de la Federación, 26 de mayo de 1976, México, D. F. En Línea: http:// www.diputados.gob.mx/LeyesBiblio/pdf/133.pdf. Consultado el 7 de febrero de 2014.

ESTADOS UNIDOS MEXICANOS (1983): «Ley de Planeación». Diario Oficial de la Federación, 5 de enero de 1983, México, D. F. En línea: http://www.diputados.gob. mx/LeyesBiblio/pdf/59.pdf. Consultado el 7 de febrero de 2014.

ESTADOS UNIDOS MEXICANOS (1988): «Ley General del Equilibrio Ecológico y la Protección al Ambiente, LGEEPA». Diario Oficial de la Federación, 28 de enero 
de 1988, México, D. F. En línea: http://www.diputados.gob.mx/LeyesBiblio/pdf/148. pdf. Consultado el 7 de febrero de 2014.

ESTADOS UNIDOS MEXICANOS (1993): «Ley General de Asentamientos Humanos». Diario Oficial de la Federación, 21 de julio de 1993, México, D. F. En línea: http:// www.diputados.gob.mx/LeyesBiblio/pdf/133.pdf. Consultado el 7 de febrero de 2014.

ESTADOS UNIDOS MEXICANOS (2012): «Programa de Ordenamiento Ecológico General del Territorio». Diario oficial de la Federación, 7 de septiembre de 2012, México, D. F. En línea: http://www.dof.gob.mx/nota_detalle_popup.php?codigo=5267334. Consultado el 18 de febrero de 2014.

Fernandes Barros, J., Neves Dos Santos, M. C., Pinheiro Cerdeira, R. G. (s/f): «De la zonificación ecológica-económica al ordenamiento territorial: desafíos y perspectivas de gestión territorial participativa en la amazonía brasileña». En línea: http:// www2.inecc.gob.mx/publicaciones/libros/670/cap2.pdf. Consultado el 12 de octubre de 2014.

FERrufino, C. E. (2014): «Ordenamiento territorial: diversidad, convergencia y desafíos». En línea: http://www.diariolibre.com/habitat/2013/02/22/i372506_ordenamiento-territorial-diversidad-convergencia-desafos.html. Consultado el 12 de febrero de 2014.

FUNDACIÓN CAMBIO DEMOCRÁTICO (2010): «Una aproximación al ordenamiento ambiental del territorio como herramienta para la prevención y transformación democrática de conflictos socio-ambientales». Buenos Aires.

García Moctezuma, F. (2010): «La planeación del desarrollo regional en México (19002006)». Investigaciones Geográficas n $\mathrm{n}^{\circ} 71,102-121$.

GOBIERNO DE MENDOZA (2014): «Ley No 8051: Ordenamiento Territorial y Usos de Suelo. Hacia una gestión territorial de las políticas públicas». En línea: presentaciónot-reunion-cpot-Mendoza.pdf. Consultado el 14 de febrero de 2014.

GonzÁlez Ortiz, M. A. (2014): «El Ordenamiento Comunitario del Territorio en México». Grupo Autónomo para la Investigación Ambiental, A. C. En línea: http:// www.conafor.gob.mx:8080/documentos/docs/7/0Estado $\% 20 \mathrm{del} \% 20 \mathrm{OCT} \% 20 \mathrm{en} \% 20$ M\%C3\%A9xico\%20.pdf. Consultado el 12 de febrero de 2014.

GonZÁlez SousA, R. (2009): «Logros, dificultades y desafíos de las políticas de ordenamiento y planificación territorial en Cuba» en Geografía y Territorio. Procesos territoriales y socioespaciales (MAssiris CABEZA, A., ed.). Bogotá, Colección Investigaciones EPG n ${ }^{\circ} 21,43-70$.

Hernández-Santana, J. R., Bollo-Manent M., Méndez-Linares, A. P. (2011): «Algunos indicadores biofísicos, sociales y económicos de México: plataforma para su evaluación medioambiental actual» en América Latina frente a la globalización: una visión humanista y ambiental del espacio (OLMOS CRUZ, A., MONROY GAYTAN, F., eds.). AM Editores, Toluca, 92-107.

Hernández-Santana, J. R., Bollo-Manent, M., Méndez-Linares, A. P. (2013a): «Ordenamiento ecológico general del territorio mexicano: enfoque metodológico y principales experiencias». Boletín de la Asociación de Geógrafos Españoles n ${ }^{\circ}$ 63, 33-55.

Hernández-Santana, J. R., Bollo-Manent, M., Méndez-Linares, A. P., LÓPEZ-MiGUEL, C. (2013b): «Programa de Ordenamiento Ecológico General del Territorio (POEGT) de México: una primera aproximación en el sexenio 2006-2012» en La 
politica de Ordenamiento Territorial en México: de la teoría a la práctica (SÁNCHEZ SALAZAR, M. T.; BOCCO VERDINELLI, G.; CASADO IZQUIERDO, J. M., coords.). México, D. F., UNAM-SEMARNAT, $1^{\mathrm{a}}$ ed., 343-379.

HeRnÁNDEZ-SANTANA, J. R. (2014). «El arte de hilvanar los intereses territoriales». GeocritiQ, 10 julio de 2014. En línea: http://www.geocritiq.com/2014/07/el-arte-dehilvanar-los-intereses-territoriales-2/. Consultado el 11 de octubre de 2014.

INSTITUTO DE INVESTIGACIONES DE LA AMAZONIA PERUANA-IIAP, MINISTERIO DEL AMBIENTE DEL PERÚ, SECRETARÍA GENERAL DE LA COMUNIDAD ANDINA, DEUTSCHE GESELLSCHAFT FÜR TECHNISCHE ZUSAMMENARBEIT (2010): «Ordenamiento territorial de la región andino-amazónica». Iquitos.

INAFED, SECRETARÍA DE GOBERNACIÓN (2014): «Enciclopedia de los Municipios y Delegaciones de México». En línea: http:/www.e-local.gob.mx/wb2/ELOCAL/ELOC_Enciclopedia. Consultado el 17 de febrero de 2014.

INSTITUTO NACIONAL DE LENGUAS INDÍGENAS (INALI) (2010): «Catálogo de las lenguas indígenas nacionales: Variantes lingüísticas de México con sus autodenominaciones y referencias geoestadísti-cas». Diario Oficial de la Federación, 14 de enero de 2008. México, D. F., 31-112.

INE-SEMARNAP (2000): «El ordenamiento ecológico del territorio. Logros y retos para el desarrollo sustentable 1995-2000». México, D. F.

Iturriaga Meneses, J. (2003): «Ordenamiento territorial en Chile: instituciones, instrumentos, problemas y propuestas». Tesis de Magister en Asentamientos Humanos y Medio Ambiente, Pontificia Universidad Católica de Chile, Santiago de Chile.

Lara Padilla, Y., Chapela Mendoza, F. (2006): «Dilemas institucionales del ordenamiento territorial» en Ordenamiento territorial comunitario: un debate de la sociedad civil hacia la construcción de politicas públicas (AnTA FonsecA, S., Arreola MuÑoz, A. A., González Ortiz, M. A., Acosta González, J., coords.). México, D. F., SEMARNAT, $1^{\mathrm{a}}$ ed., 91-110.

LIRA Cossio, L. (2009): «Nuevos paradigmas de planificación territorial en América Latina» en Geografía y Territorio. Procesos territoriales y socioespaciales (MASSIRIS CABeza, A., ed.). Bogotá, Colección Investigaciones EPG nº 21, 121-139.

López Blanco, J. (2008): «Regionalización ambiental (biofísica) nacional». En: Caracterización y diagnóstico integrado para el Programa de Ordenamiento Ecológico General del Territorio (Hernández-Santana, J. R., coord.). SEMARNAT, México, D. F., t. I-II, 319-353.

López MuÑoz, W. (2011): «Estructura formal para el ordenamiento territorial de Chile Tricontinental». Urbano $\mathrm{n}^{\circ} 23,28-37$.

Lozano Castro, A. (2013): «Ordenamiento Territorial y Buen Vivir - Sumak Kawsay: Retos del Estado Plurinacional Ecuatoriano». Runa Yachachiy, Revista electrónica digital. En línea: http://www.alberdi.de/OrdTerLozI13.pdf. Consultado el 15 de febrero de 2014.

Mallea, M. I. (s/f): «Ordenamiento territorial y la dimensión ambiental de los instrumentos de planificación en Chile». Universidad de Chile, 20 p. En línea: http://www. 
achidam.cl/documentos/OT\%20y\%20dimension $\% 20$ ambiental $\% 20 \mathrm{de} \% 2010 \mathrm{~s} \% 20$ IPT.pdf. Consultado el 10 de octubre de 2014.

Marina-Berón, N., Padilla Rodríguez, C. H., Rapali, N. (2013): «Nuevo marco normativo de ordenamiento territorial en Mendoza: su aplicación en el área metropolitana». Bitácora $22 \mathrm{n}^{\circ}$ 1, 97-108.

Massiris CABEZA, A. (2006): «Políticas Latinoamericanas de OrdenamientoTerritorial: Realidad y Desafíos». Colombia, Ediciones Universidad Pedagógica y Tecnológica de Colombia, 15-63.

Massiris CabezA, A. (2009): «Diez años de planes de ordenamiento territorial municipal en Colombia: un balance» en Geografía y Territorio. Procesos territoriales y socioespaciales (Massiris CABEZA, A., ed.). Bogotá, Colección Investigaciones EPG n 21, $15-42$.

Massiris CABezA, A. (2012): «Políticas latinoamericanas de ordenamiento territorial. Realidad y desafíos» en Procesos de Ordenamiento en América Latina y Colombia (Espinoza Rico, M. A., Ramirez Castañeda, T., Rincón Avellaneda, P., SAnabria ArTunduAGA, T.). Bogotá, Universidad Nacional de Colombia, $1^{a}$ ed., 13-30.

Massiris CABezA, A. (2013): «Políticas de ordenamiento territorial en América Latina: examen comparado». BioCAN, Lima.

Massiris CABezA, A. (s/f, a): «Ordenamiento territorial y procesos de construcción regional». Biblioteca virtual Luis Ángel Arango. En línea: http://www.banrepcultural. org/blaavirtual/geografia/masir/1.htm. Consultado el 4 de octubre de 2014.

Massiris CabezA, A. (s/f, b): « Ordenamiento territorial: Experiencias internacionales y desarrollos conceptuales y legales realizados en Colombia». Biblioteca virtual Luis Ángel Arango. En línea: http://www.banrepcultural.org/blaavirtual/geografia/orden/4. htm. Consultado el 4 de octubre de 2014.

Mateo Rodríguez, J. M., Ortiz Pérez, M, A. (2001): «La degradación de los paisajes como concepción teórico-metodológica». Nueva Época, $\mathrm{n}^{\circ} 1$, Instituto de Geografía, UNAM, México, D. F..

MÉndeZ Vergara, E. (2000): «Ordenamiento territorial-ambiental: desarrollo responsable y sostenible». Revista Geográfica Venezolana Vol. 41 n², 281-301.

MINISTERIO DE PLANIFICACIÓN FEDERAL, INVERSIÓN PÚBLICA Y SERVICIOS DE PLANIFICACIÓN FEDERAL DE ARGENTINA (2014): «Argentina 2016. Política y Estrategia Nacional de Desarrollo y Ordenamiento Territorial, 1-46. En línea: http://www.cofeplan.gov.ar/html/pet/documentos/argentina_web_2016c a332ad.pdf. Consultado el 7 de febrero de 2014.

MINISTERIO DE VIVIENDA, ORDENAMIENTO TERRITORIAL Y MEDIO AMBIENTE (MVOTMA) (2010): «Directrices nacionales de ordenamiento territorial y desarrollo sostenible». En línea: http://www.vertiente.org.uy/webnew/documentos/ Directrices_OT_04-10.pdf. Consultado el 23 de febrero de 2014.

Montenegro, I., Aldo, F. (2012): «Ordenamiento territorial en el sur de Chile. Experiencia de WWF con pueblos indígenas y comunidades locales». WWF, Valdivia.

Morales Hurtado, J. (2012): «La importancia del ordenamiento territorial». Cuarto Intermedio. En línea: http://gforno.blogspot.mx/2012/07/la-importancia-del-ordenamiento.html. Consultado el 6 de octubre de 2014. 
Negrete Fernández, G.; Bocco Verdinelli, G. (2003): «El ordenamiento ecológico comunitario: una alternativa de planeación participativa en el contexto de la política ambiental de México». Gaceta ecológica n 68, 9-22.

Olivos Campos, J. R. (2014): «La democracia representativa en México». En línea: http:// derecho.posgrado.unam.mx/congresos/congreibero/ponencias/olivoscamposjoserene.pdf. Consultado el 22 de febrero de 2014.

ONAPLAN (2014): Subsecretaría de Planificación, Secretaría de Estado de Economía, Planificación y Desarrollo. En línea: http://www.onaplan.gov.do. Consultado el 14 de febrero de 2014.

Ongay Delhumeau, E.; Zorrilla Ramos, M. (2008a): «El ordenamiento ecológico general del territorio y las políticas públicas de la Administración Pública Federal». SEMARNAT, México.

Ongay Delhumeau, E.; Zorrilla Ramos, M. (2008b): «Aptitud sectorial» en Formulación de la propuesta del Programa de Ordenamiento Ecológico General del Territorio (Hernández-Santana, J. R., coord.). México, D. F., SEMARNAT, t. IV, 5-58.

ORNÉs, S. (2009): «El urbanismo, la planificación urbana y el ordenamiento territorial desde la perspectiva del derecho urbanístico venezolano». Politeia, Vol. 32, n 42 , 197-225.

Palacio Prieto, J. L., Sánchez Salazar, M. T., Hernández-Santana, J. R., Ortiz Pérez, M. A., Oropeza Orozco, O., Velásquez Montes, A., Hernández Cerda, M. E., Perevochtchikova, M., Casado Izquierdo, J. M. (2009): «Orientación metodológica, variables e indicadores físico-geográficos en el ordenamiento territorial de México» en Geografía y Territorio. Procesos Territoriales y Procesos Espaciales (Massiris CABezA, A., ed.). Bogotá, Colección Investigaciones EPG nº 21, 141-178.

Palacio Prieto, J. L. (2011): «Los estudios de Geografía en las universidades de América Latina; desarrollo, situación actual y perspectivas». Investigaciones Geográficas $\mathrm{n}^{\circ}$ 74, 107-124.

Pereira Nunes, E. (2004): «Estudio de caso en Brasil. Principales desafíos del ordenamiento territorial», Ponencia en Foro Especial Interregional de las Naciones Unidas, FIG y PC IDEA. Desarrollo de Politicas de Información Territorial en las Américas (Aguascalientes, 26 al 27 de octubre de 2004), 1-18. En línea: http://www. fig.net/pub/mexico/papers_span/ts5_nunes_span.pdf, Consultado el 5 de febrero de 2014.

Rentería Rodríguez, M. T. (2011): «Tipos y modos de la participación ciudadana en los procesos de ordenación del territorio. Dos casos para su ilustración» en Ordenamiento territorial y participación social: problemas y posibilidades (AGUILAR RoBLedo, M., Delgado lópez, E., Vázquez Solís V., Reyes Pérez, O., eds.). México, D. F., CIGA (UNAM)-INE (SEMARNAT), 447-470.

REPÚBLICA DE COLOMBIA (1997): «Plan de Ordenamiento Territorial». Diario Oficial $\mathrm{N}^{\circ}$ 43.901, Bogotá. En línea: https://www.dnp.gov.co/Portals/0/archivos/documentos/DDTS/Gestion_Publica_Territorial/

1bnormatividadley_388_1997.pdf. Consultado el 15 de febrero de 2014. 
REPÚBLICA DE VENEZUELA (1983): «Ley Orgánica de Ordenación del Territorio (LOOT)». Gaceta Oficial N 3.238 extraordinario, Caracas. En línea: http://faolex. fao.org/docs/html/ven24827.htm. Consultado el 15 de febrero de 2014.

Rodriguez Vera, R. A.; SaAvedra De La Cruz, G. (2011): «La participación social en el ordenamiento territorial. Participación o representación, un dilema legal y metodológico». en Ordenamiento territorial y participación social: problemas y posibilidades (Aguilar Robledo, M., Delgado López, E., Vázquez Solís V., Reyes Pérez, O., eds.). México, D. F., CIGA (UNAM)-INE (SEMARNAT), 241-269.

RoJAs GarcíA, O. (2010): «Ecological land management in the oil municipalities of Region V North, Chiapas: limits and perspectives of participatory community workshops». Investigaciones Geográficas n $\mathrm{n}^{\circ} 73,41-56$.

Rosete Vergés, F. A. (2006): «Semblanza histórica del ordenamiento ecológico territorial en México, una perspectiva institucional». SEMARNAT, México, D. F.

Rosete Vergés, F. A., Negrete Fernández, G. (2012): «Planeación territorial en el sureste de México: Revisión histórica del ordenamiento ecológico». Universidad y Ciencia Vol. 28, n 3, 301-311.

Rosete Vergés, F. A., Enríquez Hernández, G., Aguirre von Wobeser, E. (2013): «El componente del riesgo en el Ordenamiento Ecológico del Territorio: el caso del Ordenamiento Ecológico Regional y Marino del Golfo de México y Mar Caribe». Investigaciones Geográficas n ${ }^{\circ}$ 80, 7-20.

Salas Bourgoin, M. A. y Sulbarán Zambrano, E. (2011): «Modificación de la Ley Orgánica para La Ordenación del Territorio en Venezuela: revisión de un proceso de 10 años sin perspectivas de cristalización». Provincia n $^{\circ}$ 26, 33-66.

SÁnchez LunA, G. (2011): «Evolución legislativa de la planeación del desarrollo y la planeación urbana en México». Boletín Mexicano de Derecho Comparado. En línea: http://www.juridicas.unam.mx/publica/rev/boletin/cont/86/art/art14.htm. Consultado el 21 de enero de 2014.

Sánchez-Salazar, M. T.; Palacio Prieto, J. L. (2004): «La experiencia mexicana en la elaboración de los Programas Estatales de Ordenamiento Territorial. Diagnóstico, problemática y perspectivas desde el punto de vista de la participación del Instituto de Geografía de la UNAM». Investigaciones Geográficas n $\mathrm{n}^{\circ}$ 53, 75-97.

Sánchez-Salazar, M. T., Hernández-Santana, J. R. (2011): «Propuesta de Licenciatura en Gestión Integral del Territorio para la ENES Unidad León de la UNAM». Ponencia en VII Simposio de la Enseñanza de la Geografía en México (Querétaro, 3 al 5 de noviembre de 2011). Querétaro, Universidad Autónoma de Querétaro, 14.

Sánchez Salazar, M. T.; Casado Izquierdo, J. M.; Bocco Verdinelli, G. (2013): «La política de ordenamiento territorial en México: de la teoría a la práctica. Reflexiones sobre sus avances y retos a futuro» en La política de Ordenamiento Territorial en México: de la teoría a la práctica (SÁNCHEZ SALAZAR, M. T.; BOCCO VERDINELLI, G.; CASADO IZQUIERDO, J. M., coords.). México, D. F., UNAM-SEMARNAT, $1^{\mathrm{a}}$ ed., 19-44.

SEMARNAT (2003): «Reglamento de la Ley General del Equilibrio Ecológico y la Protección al Ambiente en materia de ordenamiento ecológico». Diario Oficial de la Federación, 8 de agosto de 2003. México, D. F., 39-58. 
SEMARNAT (2014): «Ordenamientos ecológicos decretados con o sin la participación de SEMARNAT». En línea: http://web2.semarnat.gob.mx/temas/ordenamientoecologico/. Consultado el 17 de febrero de 2014.

SENPLADES (2007): «Secretaría de Planificación y Desarrollo». En línea: http://www. planificacion.gob.ec/wp-content/uploads/downloads/2012/08/SENPLADES-Quehacemos-y-quienes-somos.pdf. Consultado el 25 de febrero de 2014.

SISCA (2014): «Participación en los esfuerzos regionales en la materia de ordenamiento territorial para el fortalecimiento de los procesos nacionales». En línea: http://www. sisca.int/actualidad/noticias/495. Consultado el 13 de febrero de 2014.

Sotomayor, P. (2014): «Ordenamiento Territorial Nacional en Ecuador». En línea: http:// www.partealta.ec/opinion/destacados/153-editorial/15761-ordenamiento-territorialnacional-en-ecuador. Consultado el 15 de febrero de 2014.

SUBDERE (2011): «Plan de Ordenamiento Territorial». Santiago de Chile.

Thomas Bohórquez, J. A. (2013): «Evaluación de la vulnerabilidad social ante amenazas naturales en Manzanillo (Colima). Un aporte de método». Investigaciones Geográficas $\mathrm{n}^{\circ} 81,79-93$.

Torres-FiLho, W. (2010): « Desarrollo local regional y ordenamiento territorial en Brasil». En línea: http://vinculando.org/articulos/sociedad_america_latina/planeacion_estrategica_desarrollo_local_regional_brasil.html. Consultado el 9 de octubre de 2014.

VILANova, E. (2014): «El ordenamiento territorial: Planes de ordenación del territorio. Plan actual de ordenamiento territorial de Venezuela». En línea: http://www.academia. edu/1742599/El_ordenamiento_territorial_Planes_de_ordenacion_del_territorio. Planes_de_ordenamiento_territorial_de_Venezuela. Consultado el 15 de febrero de 2014.

Werner, G., Bemmerlein-Lux, F., Zuñiga, M. E. (1995): «Ordenamiento territorial y planificación ambiental en Chile». Santiago de Chile.

Zaragoza Alvarez, R. A., Peters Recagno, E. M., Bollo-Manent, M., Hernández-SanTANA, J. R. (2013): «Áreas Prioritarias de Geo-conservación de la biodiversidad en la Península de Baja California, México». Journal of Latin American Geography, Vol. $12, \mathrm{n}^{\circ} 3,7-31$. 